\title{
Is there any possibility that plasma could selectively modify polymer surfaces?
}

\author{
N. Inagaki \\ Laboratory of Polymer Chemistry, Faculty of Engineering \\ Shizuoka University, 3-5-1 Johoku, Hamamatsu, 432-8561 Japan \\ tcninag@ipc.shizuoka.ac.jp
}

\begin{abstract}
In order to resolve susceptibility of PTFE(polytetrafuloroethylene) and $\mathrm{PE}$ (polyethylene) against $\mathrm{H}_{2}$ and $\mathrm{O}_{2}$ plasmas, modification reactions of ETFE(ethylene-co-tetrafluoroethylene) surfaces by $\mathrm{H}_{2}, \mathrm{O}_{2}$, and $\mathrm{Ar}$ plasmas were investigated from viewpoint of chemistry. The chemical modification involved defluorination and oxidation reactions. These reactions were favorable in the remote $\mathrm{H}_{2}$ and Ar plasmas, but were unfavorable in the remote $\mathrm{O}_{2}$ plasma. $\mathrm{C}-\mathrm{H}$ and $\mathrm{C}-\mathrm{F}$ components in the ETFE surfaces were evenly modified by the remote plasma. Either of $\mathrm{CH}_{2}-\mathrm{CH}_{2}$ or $\mathrm{CF}_{2}-\mathrm{CF}_{2}$ component was not selectively modified
\end{abstract}

Keywords: polytetrafluoroethylene, polyethylene, ethylene-co-tetrafluoroethylene, surface modification, plasma treatment, contact angle, XPS, ATR IR spectra

\section{Introduction}

Plasma treatment is a useful technology in the field of polymer surface modification. Once every polymer surface is exposed to plasma just for a few minutes, the exposed surface causes to be changed in surface properties such as hydrophobicity. Even polytetrafluoroethylene (PTFE) can easily be modified by plasma. For example, Figure 1 shows contact angle of water on PTFE surfaces exposed to oxygen and hydrogen plasmas as a function of the exposure time. When PTFE surfaces are exposed to the hydrogen plasma only for $60 \mathrm{~s}$, the surfaces show a large decrease in water contact angle from 106 to 80 degrees. Oxygen plasma cannot modify PTFE surfaces into so hydrophilic as the hydrogen plasma does. On the other hand, polyethylene (PE) surfaces are well modified into hydrophilic by both hydrogen and oxygen plasmas (Figure 1). Why is there difference in plasma susceptibility between PTFE and PE surfaces? When polymer surface containing $\mathrm{CF}_{2}-\mathrm{CF}_{2}$ and $\mathrm{CH}_{2}-\mathrm{CH}_{2}$ components is exposed to oxygen or hydrogen plasma, does the oxygen plasma modify $\mathrm{CH}_{2}-\mathrm{CH}_{2}$ component alone on the polymer surface? Does the hydrogen plasma modify both $\mathrm{CF}_{2}-\mathrm{CF}_{2}$ and $\mathrm{CH}_{2}-\mathrm{CH}_{2}$ components

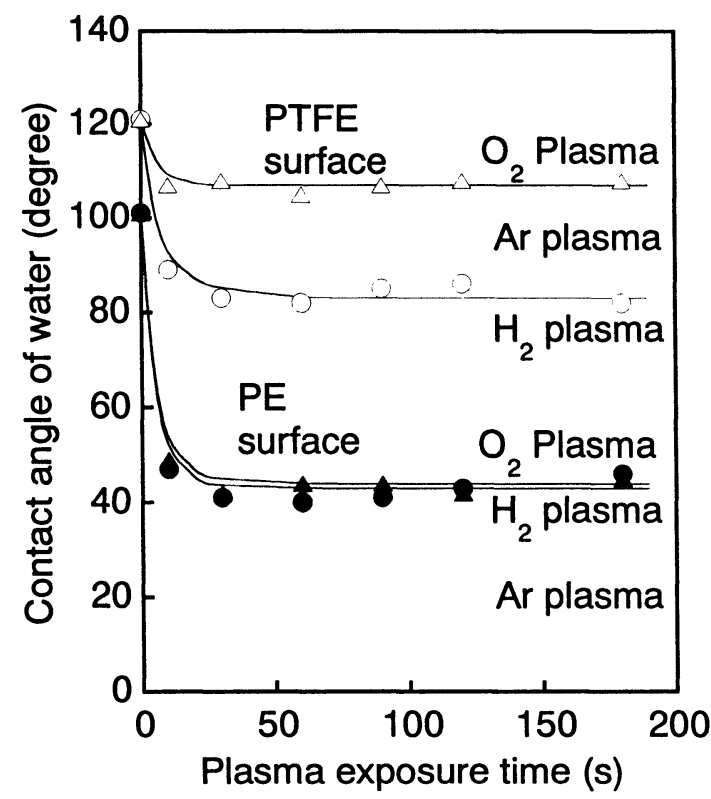

Figure 1 Contact angle of water on PTFE and PE surfaces treated with $\mathrm{H}_{2}$ and $\mathrm{O}_{2}$ plasmas as a function of plasma exposure time. 
on the polymer surface? If such modifications are possible, polymer surfaces can be modified in nanometer scale.

Ethylene-co-tetrafluoroethylene, ETFE, is an alternating copolymer of ethylene and tetrafluoroethylene. Physical and chemical properties of ETFE are similar to those of polytetrafluoroethylene and other fluoropolymers such as copolymers of tetrafluoroethylene and hexafluoropropylene, FEP; and of tetrafluoroethylene and perfluoro(alkyl vinyl ether), PFA. When ETFE surface is exposed to plasma, what modification will occur on the ETFE surface? Can $\mathrm{CH}_{2}$ components in the ETFE be selectively modified by oxygen plasma? Can hydrogen plasma modify homogeneously both $\mathrm{CH}_{2}$ and $\mathrm{CF}_{2}$ components in ETFE?

In this study, we have focused on what surface reactions occur in exposing ETFE surface to plasmas. Hydrogen plasma, oxygen plasma, and argon plasma were used for surface modification.

\section{Experimental}

\subsection{Materials}

Ethylene-co-tetrafluoroethylene, ETFE, film received from Asahi Glass Co. Ltd., Japan (trade name, Fluon ETFE; $100 \mu \mathrm{m}$ thickness) was provided as specimens for plasma modification. The concentration of $\mathrm{CH}_{2}-\mathrm{CH}_{2}$ and $\mathrm{CF}_{2}-\mathrm{CF}_{2}$ components in the ETFE film was 47 and $53 \mathrm{~mol} \%$, respectively, which were estimated from the XPS analyses.

2.2. Modifications of ETFE Films by Remote and Direct Plasmas

A special reactor of which details had been reported elsewhere [1] was used for the modification of ETFE surfaces. The ETFE specimens were positioned in the plasma reactor, and $\mathrm{H}_{2}, \mathrm{O}_{2}$, or Ar was introduced into the plasma reactor with a flow rate of $10 \mathrm{~cm}^{3}$ (STP)/min adjusted by a mass flow controller. The system was maintained at a pressure of $13.3 \mathrm{~Pa}$ by adjusting the vacuum valve. The plasma was operated at an rf power of $100 \mathrm{~W}$ at $13.56 \mathrm{MHz}$ frequencies for given duration (5 $180 \mathrm{~s})$.

2.3. Contact Angle of Water on the plasmamodified PET Film Surfaces.

Contact angles of water on the ETFE film surfaces treated with the remote and direct plasmas were measured at $20^{\circ} \mathrm{C}$ by means of the sessile drop method [2]. A contact angle meter (Erma Co. Ltd., Japan, model G-1) was used for the measurement. An average of the contact angle was determined from ten times measurement with an experimental error of 3 - 4 degrees.

\section{Results and Discussion}

When polymer surfaces are exposed to plasma, two main reactions are initiated on the surfaces. One is introduction reaction of functional groups such as carbonyl, carboxyl, etc. onto the polymer surfaces to be modified into hydrophilic. The other is degradation reaction of polymer chains. Weight loss of the polymer materials occurs, and degradation products deposit on the surfaces. The former reaction is a genuine process for the surface modification. The latter reaction is a burdensome process for the surface modification, because polymer chains on the surface are injured, and the surfaces are contaminated with degradation products. We never escape from the degradation reactions as long as we use plasma for surface modification, because the introduction and degradation reactions occur simultaneously. From this viewpoint, we have to seek modification conditions for minimizing the degradation reactions.

Preliminary experiments showed that the degradation reactions could be minimize by using the remote plasma for the modification of ETFE surfaces. We call the plasma exposures at a sample position of 0 and $80 \mathrm{~cm}$ from the plasma zone as the direct plasma treatment and the remote plasma treatment, respectively [1]. From now, we use the remote plasma for subsequent experiments of the ETFE surface modification.

\subsection{Contact angle of water on plasma-modified ETFE surfaces \\ The ETFE film is an alternating copoly-} mer of $\mathrm{CH}_{2}-\mathrm{CH}_{2}$ and $\mathrm{CF}_{2}-\mathrm{CF}_{2}$ components. Figure 1 forecasts that surface modification induced on the ETFE surfaces may be a mixture of the modifications occurring on PE and PTFE surfaces. Is the forecast of the modification true? If it is true, the contact angel on modified the ETFE surfaces has to show strong dependence on what plasma was used for the modification. Table 1 compares the contact angle among the PTFE surfaces modified by the remote $\mathrm{H}_{2}, \mathrm{O}_{2}$, and $\mathrm{Ar}$ plasmas. The ETFE surfaces were easily modified with the remote $\mathrm{H}_{2}$ plasma, and the contact 
angle on their surfaces was 44 degrees, which was as low as the contact angle for the modified PE surface (40 degrees). However, the ETFE sur-

Table 1 Contact angle of water on ETFE, PE, and PTFE surfaces exposed to remote plasmas for $60 \mathrm{~s}$

\begin{tabular}{lccc}
\hline Kind of plasma & \multicolumn{3}{c}{ Contact angle on modified surfaces (degrees) } \\
& ETFE surfaces & PE surfaces & PTFE surfaces \\
\hline H2 plasma & 44 & 40 & 82 \\
O2 plasma & 80 & 44 & 105 \\
Ar plasma & 54 & 30 & 102 \\
None (unmodified) & 106 & 101 & 121 \\
\hline
\end{tabular}

faces could be barely modified by the remote $\mathrm{O}_{2}$ and $\mathrm{Ar}$ plasmas. Comparison in contact angle among the plasma-modified ETFE, PE, and PTFE surfaces gives us some questions.

(1) Why could the ETFE surfaces be modified with the remote $\mathrm{H}_{2}$ plasma as easily as the $\mathrm{PE}$ surfaces, even though the ETFE surfaces contain $\mathrm{CF}_{2}-\mathrm{CF}_{2}$ components in the polymer chains?

(2) Why could the ETFE surface be barely modified with the remote $\mathrm{O}_{2}$ plasma, even though the ETFE surfaces possess $\mathrm{CH}_{2}-\mathrm{CH}_{2}$ components in the polymer chains?

3.2. XPS spectra for the ETFE surfaces modified with remote plasmas

Atomic composition for the ETFE surfaces modified with the remote $\mathrm{H}_{2}, \mathrm{O}_{2}$, and $\mathrm{Ar}$ plasmas was estimated from relative intensities of may be due to post reactions of carbon radicals formed on the ETFE surfaces by bombardment of electrons and ions in the plasmas.

Defluorination estimated from the F/C atomic ratio was $55 \%$ by the remote $\mathrm{H}_{2}$ plasma, $51 \%$ by the remote Ar plasma, and $25 \%$ by the remote $\mathrm{O}_{2}$ plasma. The oxidation also was in the order of modification by the remote $\mathrm{H}_{2}$ plasma > modification by the remote Ar plasma $>$ modification by the remote $\mathrm{O}_{2}$ plasma. These defluorination and oxidation may be closely related to the contact angle on the plasma-modified ETFE surfaces. Details of defluorination and oxidation reactions were investigated from data of narrow scanning C1s and O1s core level spectra.

The C1s spectra for the ETFE surfaces modified with the remote $\mathrm{H}_{2}, \mathrm{O}_{2}$, and Ar plasmas were decomposed into four components, which appeared at $286.1-286.5 \mathrm{eV}$ (C1s component \#1), at $287.5-287.9 \mathrm{eV}$ (C1s component \#2), at 289.0 - $290.0 \mathrm{eV}$ (C1s component \#3), and at 291.1 $291.4 \mathrm{eV}$ (C1s component \#4). The O1s spectra also were decomposed into two components, which appeared at $531.3-531.4 \mathrm{eV}$ (O1s component \#1) and at 533.6 - 533.8 eV (O1s component $\# 2$ ). These analytical results are summarized in Table 2. The binding energy for the O1s components \#1 and \#2 gives us detailed information on chemical composition of the oxygen functional groups formed on the plasma-modified ETFE surfaces. If oxygen functional groups such as car-

Table 2 XPS spectra for plasma-modified ETFE surfaces

\begin{tabular}{|c|c|c|c|c|c|c|c|c|}
\hline \multirow[t]{2}{*}{ Kind of plasma } & \multicolumn{2}{|c|}{ Atomic composition } & \multicolumn{4}{|c|}{$\mathrm{Cls}$ components (mol\%) } & \multicolumn{2}{|c|}{ Ols components (mol\%) } \\
\hline & $\mathrm{F} / \mathrm{C}$ ratio & $\mathrm{O} / \mathrm{C}$ ratio & Comp. \#1 & Comp. \#2 & Comp. \#3 & Comp. \#4 & Comp. \#1 & Comp. \#2 \\
\hline $\mathrm{H} 2$ plasma & 0.38 & 0.22 & 48 & 18 & 10 & 24 & 37 & 63 \\
\hline $\mathrm{O} 2$ plasma & 0.68 & 0.17 & 40 & 11 & 9 & 40 & 45 & 55 \\
\hline Ar plasma & 0.45 & 0.19 & 40 & 21 & 13 & 26 & 37 & 63 \\
\hline None (unmodifiede) & e) 1.14 & $<0.03$ & 47 & & & 53 & & \\
\hline
\end{tabular}

C1s, F1s, and O1s core level spectra. The estimation results are summarized in Table 2. All plasma-modified ETFE surfaces showed lower F/C atomic ratio $(0.38-0.68)$ than the unmodified ETFE surface $(\mathrm{F} / \mathrm{C}$ ratio $=1.14)$, and higher $\mathrm{O} / \mathrm{C}$ atomic ratio $(0.17-0.22)$. These changes indicates that the plasma exposure led to defluorination and oxidation reactions on the ETFE surfaces. The oxidation reactions occurring on the ETFE surfaces bonyl and hydroxyl groups are formed on fluorinated carbon atoms, the oxygen groups will be strongly influenced by the fluorine atoms and will appear at higher binding energy regions (by about $2 \mathrm{eV}$ ) than the oxygen groups formed on not-fluorinated carbons. As for the 01s components \#1 and \#2 at 531.3 - 531.4 and 533.6 - 533.8 $\mathrm{eV}$, there is no indication that some fluorine atoms influenced their components into shifting their 
binding energy. The 01 s components \#1 and \#2 are corresponded to typical $\underline{\mathrm{O}}=\mathrm{C}$ groups $(532.2 \mathrm{eV}$ in poly(methylacrylate)) and $\underline{\mathrm{O}}-\mathrm{C}$ groups (533.7 $\mathrm{eV}$ in poly(methylacrylate)). Since there was no shift toward higher binding energy regions, the O1s components \#1 and \#2 could be assigned $\underline{O}=C$ groups such as $-\mathrm{CH}_{2}-\mathrm{C}(\mathrm{O})-\mathrm{CF}_{\mathrm{X}^{-}}$and $-\mathrm{CF}_{\mathrm{X}}-\mathrm{C}(\mathrm{O})-\mathrm{O}-$, and $\underline{\mathrm{O}}-\mathrm{C}$ groups such as $-\mathrm{CF}_{\mathbf{X}}-\mathrm{C}(\mathrm{O})-\mathrm{O}-, \quad-\mathrm{CH}_{2}-\mathrm{CH}(\mathrm{O}-\mathrm{R})-\mathrm{CH}_{2}-\quad$ and $-\mathrm{CH}_{2}-\mathrm{CH}(\mathrm{O}-\mathrm{R})-\mathrm{CF}_{\mathrm{X}^{-}}$, respectively.

The C1s spectra also are strongly influenced by the fluorine atoms if there are fluorine atoms on carbons. Fluorine effects will cause binding energy shift on C1s core level of $2.9 \mathrm{eV}$ ( $\alpha$ effect) and $0.9 \mathrm{eV}(\beta$ effect). From these effects, the four $\mathrm{C} 1 \mathrm{~s}$ components constructing the $\mathrm{C} 1 \mathrm{~s}$ spectra could be assigned - $\mathrm{CH}_{2}-\mathrm{CH}_{2}-\mathrm{CF}_{2}$ - and $-\mathrm{CH}_{2}-\mathrm{CH}(\mathrm{O}-\mathrm{R})-\mathrm{CH}_{2}-$ (C1s component \#1), $-\mathrm{CH}_{2}-\mathrm{CHF}-\mathrm{CH}_{2}-$ and $-\mathrm{CH}_{2}-\mathrm{CH}(\mathrm{O}-\mathrm{R})-\mathrm{CF}_{\mathrm{x}^{-}}(\mathrm{C} 1 \mathrm{~s}$ component \#2), $\quad-\mathrm{CH}_{2}-\mathrm{CHF}_{-}-\mathrm{CF}_{2}$, $-\mathrm{CH}_{2}-\mathrm{C}(\mathrm{O})-\mathrm{CF}_{\mathrm{X}^{-}}$, and $-\mathrm{CF}_{\mathrm{X}^{-}}-\mathrm{C}(\mathrm{O})-\mathrm{O}-\quad(\mathrm{C} 1 \mathrm{~s}$ component \#3), and - $\mathrm{CH}_{2}-\mathrm{CF}_{2}-\mathrm{CF}_{2}-(\mathrm{C} 1 \mathrm{~s}$ component \#4). The underlined carbon atoms mean the objective carbons in the assignment. As for the C1s spectrum of the unmodified ETFE surface, the components at 286.3 and $291.2 \mathrm{eV}$ were assigned $-\mathrm{CH}_{2}-\mathrm{CH}_{2}-\mathrm{CF}_{2}-$ and $-\mathrm{CH}_{2}-\mathrm{CF}_{2}-\mathrm{CF}_{2}-$ groups, respectively. Their relative concentration was 47 and $53 \mathrm{~mol} \%$, respectively. This assignment indicates that the ETFE film is an alternating copolymer composing of $\mathrm{CH}_{2}-\mathrm{CH}_{2}$ and $\mathrm{CF}_{2}-\mathrm{CF}_{2}$ sequences, and contains no sequence of $-\mathrm{CH}_{2}-\mathrm{CH}_{2}-\mathrm{CH}_{2}-\mathrm{CH}_{2}$ - and $-\mathrm{CF}_{2}-\mathrm{CF}_{2}-\mathrm{CF}_{2}-\mathrm{CF}_{2}-$ All plasma-modified ETFE surfaces showed large decreases of the $\mathrm{C} 1 \mathrm{~s}$ component \#4, new appearance of the $\mathrm{C} 1$ s components \#2 and \#3, and small changes of the C1s component \#1 (Table 2). These changes indicate that C-F bonds (C1s component \#4) in the ETFE polymers were modified into $\mathrm{C}-\mathrm{H}$ or $\mathrm{C}-\mathrm{O}$ bonds (C1s components \#2 and \#3) by the plasma exposure. The modification was favorably initiated by the remote $\mathrm{H}_{2}$ and $\mathrm{Ar}$ plasmas, but was barely initiated by the remote $\mathrm{O}_{2}$ plasma. However, complete modification of $\mathrm{CF}_{2}-\mathrm{CF}_{2}$ groups into $\mathrm{CH}_{2}-\mathrm{CH}_{2}$ groups (substitution of four hydrogen atoms for four fluorine atoms in $\mathrm{CF}_{2}-\mathrm{CF}_{2}$ groups) was never accomplished. If the complete modification were possible, $-\mathrm{CH}_{2}-\mathrm{CH}_{2}-\mathrm{CH}_{2}-$ groups (which is expected to appear at $285.0 \mathrm{eV}$.) would appear on the C1s spectra.

How were $\mathrm{C}-\mathrm{H}$ bonds in the ETFE surface modified by the plasma exposure? Table 2 shows that there were small changes in the $\mathrm{C} 1 \mathrm{~s}$ component \#1 among the plasma-modified ETFE surfaces. The change was from $47 \mathrm{~mol} \%$ to 48 mol\% for the remote $\mathrm{H}_{2}$-plasma-modified ETFE surface, and to $40 \mathrm{~mol} \%$ for the remote $\mathrm{O}_{2}$ - and Ar-plasma-modified ETFE surfaces. The C-H modification by the remote $\mathrm{H}_{2}$ plasma may be distinct from that by the remote $\mathrm{O}_{2}$ and Ar plasmas. However, details of the C-H modification are not clear because XPS gives us no information concerning the $\mathrm{C}-\mathrm{H}$ chemistry. The $\mathrm{C}-\mathrm{H}$ modification will be discussed from data accumulated by IR spectroscopy.

3.5. ATR IR spectra for the ETFE surfaces modified with remote plasmas.

XPS spectra give us useful information as to chemical composition of polymer surface, but do not led to information on chemistry of $\mathrm{C}-\mathrm{H}$ structures. IR spectra give us useful information on chemistry of C-H structures in place of XPS spectra. The remote $\mathrm{H}_{2}, \mathrm{O}_{2}$, and $\mathrm{Ar}$ plasma-modified ETFE surfaces showed similar ATR IR spectra to the unmodified ETFE surface. Characteristic absorptions due to $\mathrm{C}-\mathrm{H}$ and $\mathrm{C}-\mathrm{F}$ bonds appeared at 2976 and $2882 \mathrm{~cm}^{-1}$ (C-H stretching vibration), at 1454, 1325 and $972 \mathrm{~cm}^{-1}$ (C-H deformation vibration), and at 1251, 1168, and $1047 \mathrm{~cm}^{-1}$ (C-F stretching vibration) on the IR spectra. To distinguish the plasma-modified ETFE surfaces from the unmodified ETFE surface, differential spectra were obtained using a computer processing. A chief distinction of the differential spectra was put into two categories: One was the absorptions due to $\mathrm{C}-\mathrm{H}$ and $\mathrm{C}-\mathrm{F}$ vibrations (3000 $2900,1500-1400,1300-1200 \mathrm{~cm}^{-1}$ ). The intensity of these absorptions was decreased by the remote plasma exposure. The other was the absorptions due to $\mathrm{C}=\mathrm{O}$ vibrations $(1800-1600$ $\mathrm{cm}^{-1}$ ). New absorptions appeared at 1757,1720 , and $1672 \mathrm{~cm}^{-1}$ (Figure 2).

In order to analyze the $\mathrm{C}-\mathrm{H}$ and $\mathrm{C}-\mathrm{F}$ modification, C-H/C-F intensity ratios for the remote $\mathrm{H}_{2}, \mathrm{O}_{2}$, and Ar plasma-modified ETFE surfaces were calculated from these differential spectra (Table 3). Absorptions at $2975 \mathrm{~cm}^{-1}$ (C-H 
stretching vibration), at $1455 \mathrm{~cm}^{-1}$ (C-H deformation vibration), and at $1251 \mathrm{~cm}^{-1}$ (C-F stretching vibration) were chosen for the calculation of $\mathrm{C}-\mathrm{H} / \mathrm{C}-\mathrm{F}$ intensity ratios. The $\mathrm{C}-\mathrm{H} / \mathrm{C}-\mathrm{F}$ intensity tion of the three carbonyl groups (ester, carbonyl, and $\alpha, \beta$-unsaturated carbonyl groups) on the ETFE surfaces. The modification by the remote $\mathrm{H}_{2}$ and $\mathrm{O}_{2}$ plasmas formed the ester and carbonyl

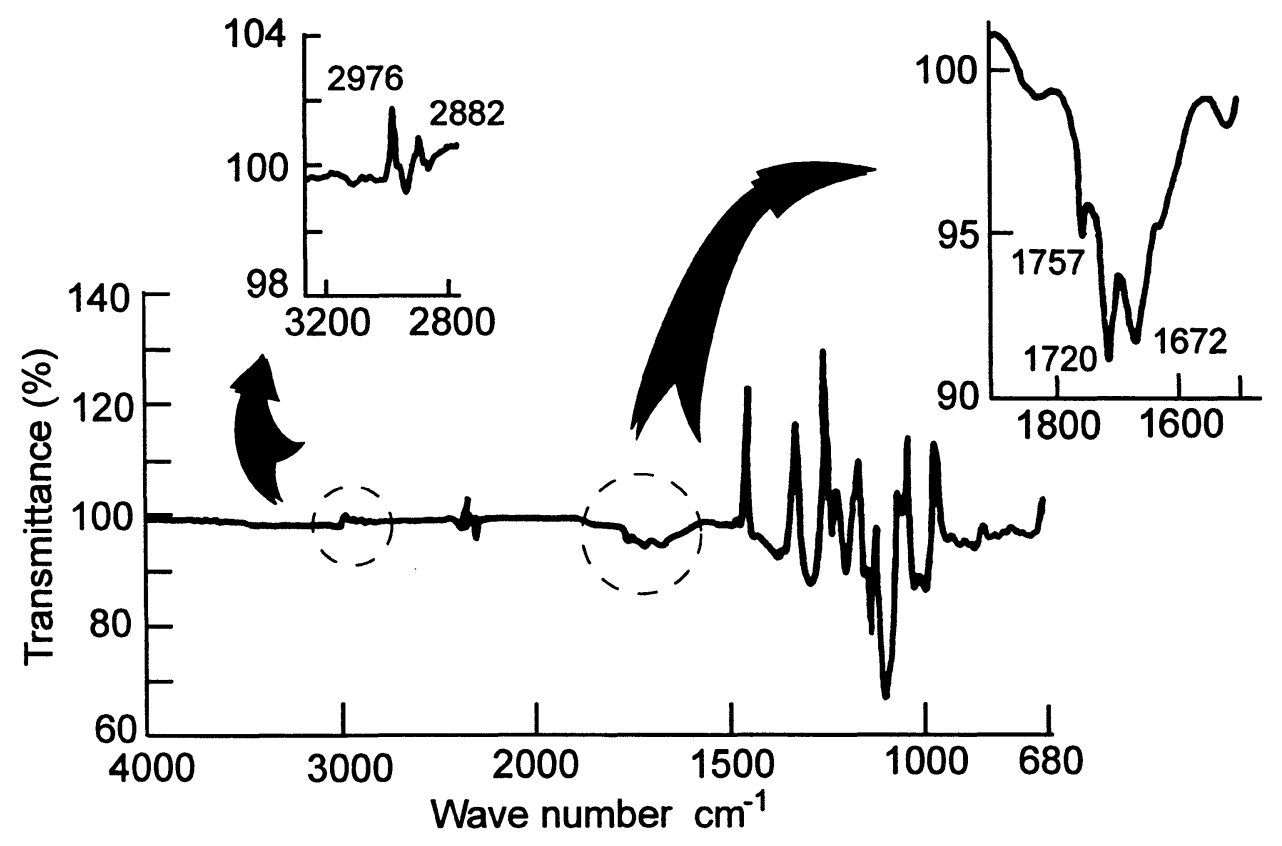

Figure 2 Differential IR spectrum for remote Ar plasma-modified ETFE surface

ratios, as shown in Table 3, were in $1.0-1.1$, and there was less difference in the C-H/C-F intensity ratios among the evenly modified by the three remote plasma-modified ETFE surfaces. The results of the calculation indicate that the $\mathrm{C}-\mathrm{H}$ and $\mathrm{C}-\mathrm{F}$ bonds were the remote plasma exposure, and that either of $\mathrm{CH}_{2}-\mathrm{CH}_{2}$ or $\mathrm{CF}_{2}-\mathrm{CF}_{2}$ component was not selectively modified.

On the other hand, as for the new absorptions due to $\mathrm{C}=\mathrm{O}$ groups $\left(1800-1600 \mathrm{~cm}^{-1}\right)$, is there any effect of the remote plasma exposure on the formation of the $\mathrm{C}=\mathrm{O}$ groups on the ETFE surfaces? Three new absorptions appeared at 1757, 1720 , and $1672 \mathrm{~cm}^{-1}$ when the ETFE surfaces were modified with the remote $\mathrm{H}_{2}, \mathrm{O}_{2}$, and $\mathrm{Ar}$ plasmas. These absorptions at 1757,1720 , and $1672 \mathrm{~cm}^{-1}$ were assigned $\mathrm{C}=\mathrm{O}$ stretching vibrations in ester groups $(\mathrm{C}(\mathrm{O})-\mathrm{O}-\mathrm{C})$, carbonyl groups $(\mathrm{C}=\mathrm{O})$, and $\alpha, \beta$-unsaturated carbonyl groups $(\mathrm{C}(\mathrm{O})-\mathrm{CH}=\mathrm{CH})$, respectively. The relative intensity of these absorptions against the absorption at $1757 \mathrm{~cm}^{-1}$ was calculated from the differential spectra data, and tabulated in Table 3 . The remote plasma exposure did not always led to forma- groups, but did not form the $\alpha, \beta$-unsaturated carbonyl groups. The remote Ar plasma formed $\alpha$, $\beta$-unsaturated carbonyl groups as well as ester and carbonyl groups on the ETFE surface. In this sense, the remote Ar plasma exposure is distinguished from the other two plasmas, the remote $\mathrm{H}_{2}$ and $\mathrm{O}_{2}$ plasmas. We cannot yet interpret here what modification reactions occurred in exposing to the remote $\mathrm{Ar}$ plasma to form the $\alpha$, $\beta$-unsaturated carbonyl groups on the ETFE surfaces.

\section{Conclusions}

$\mathrm{H}_{2}$ plasma can modify PTFE surfaces into hydrophilic, but $\mathrm{O}_{2}$ plasma cannot modify. On the other hand, both $\mathrm{H}_{2}$ and $\mathrm{O}_{2}$ plasmas can modify PE surfaces into hydrophilic. In order to resolve why there is difference in plasma susceptibility between PTFE and PE surfaces, ETFE surface that was an alternating copolymer of tetrafluoroethylene and ethylene was modified by $\mathrm{H}_{2}$, $\mathrm{O}_{2}$, and Ar plasmas. What reactions occurred on the ETFE surfaces was investigated from viewpoint of chemistry. We concluded as follows. 
Table 3 Absorption intensity of C-H, C-F, and $\mathrm{C}=\mathrm{O}$ bonds

\begin{tabular}{lccccc}
\hline Kind of plasma & \multicolumn{2}{l}{ Intensity ratios of } & \multicolumn{3}{c}{ Relative intensity of $\mathrm{C}=\mathrm{O}$ bonds } \\
& $\mathrm{C}-\mathrm{H}(\mathrm{I}) / \mathrm{C}-\mathrm{F}$ & $\mathrm{C}-\mathrm{H}(\mathrm{II}) / \mathrm{C}-\mathrm{F}$ & $\mathrm{C}(\mathrm{O})-\mathrm{C}$ & $\mathrm{C}=\mathrm{O}$ & $\mathrm{C}(\mathrm{O})-\mathrm{CH}=\mathrm{CH}$ \\
\hline $\mathrm{H} 2$ plasma & 1.1 & 1.1 & 1.0 & 1.3 & 0 \\
O2 plasma & 1.0 & 1.1 & 1.0 & 1.8 & 0 \\
Ar plasma & 1.0 & 1.0 & 1.0 & 1.7 & 1.4 \\
\hline
\end{tabular}

1. The chemical modification process involved defluorination and oxidation reactions on the ETFE surfaces. These modification reactions were favorable in the remote $\mathrm{H}_{2}$ and $\mathrm{Ar}$ plasmas, but were unfavorable in the remote $\mathrm{O}_{2}$ plasma.

2. Modification of $\mathrm{C}-\mathrm{H}$ and $\mathrm{C}-\mathrm{F}$ components by the remote plasma occurred evenly. Either of $\mathrm{CH}_{2}-\mathrm{CH}_{2}$ or $\mathrm{CF}_{2}-\mathrm{CF}_{2}$ component was not selectively modified.

\section{Acknowledgment}

We acknowledge Dr. M. Kawabe (Nitto

Denko Co., Japan) for helpful assistance with ATR
IR spectroscopy measurements.

\section{References}

1. Y. Yamada, T. Yamada, S. Tasaka, and N. Inagaki, Macromolecules, 29 (1996) 4331 4339.

2. F. Garbassi, M. Morra, E. Occhiello, Chapter 4 Surface Energetics and Contact Angle, In Polymer Surfaces from Physics to Technology; Wiley, Chichester, UK, (1994) p. 161.

3. D. T. Clark, W. J. J. Feast, Macromol. Sci., Revs. Macromol. Chem., C12 (1975) 191 286. 